E-ISSN : 2549-6581

DOI: 10.21776/ub.JOIM.2021.005.03.5

Artikel Hasil Penelitian

Diterima : 6 Desember 2021

Direview : 20 Oktober 2021

Dimuat : Desember 2021- Maret 2022

\section{OPEN ACCESS}

Journal of Issues in Midwifer

\title{
Perubahan Pengetahuan Ibu Hamil Mengenai Tanda Bahaya Kehamilan Menggunakan Media Augmented Reality
}

\author{
Rosnadila Humaira Gunawan ${ }^{1 *}$, Astuti Dyah Bestari ${ }^{2}$, Merry Wijaya ${ }^{2}$, Didah ${ }^{2}$, \\ Ariyati Mandiri ${ }^{2}$ \\ 1*) Program Studi Kebidanan, Fakultas Kedokteran, Universitas Padjadjaran, email: \\ rosnadila17001@mail.unpad.ac.id ; tlp : +6281321194104 \\ ${ }^{2}$ Program Studi Kebidanan, Fakultas Kedokteran, Universitas Padjadjaran
}

\begin{abstract}
The indirect cause of maternal death in Indonesia is " $3 T$ " factors, one of which is being late in knowing the danger signs of pregnancy. Health workers need to be aware of this because there is currently a pandemic that can make limited time for pregnancy checks. It can cause pregnant women to not have enough time for health education about the dangerous signs of pregnancy, so we need the right media for health education about danger signs of pregnancy. Industrial revolution 4.0 makes us unable to avoid using technology, including in the world of health. Augmented reality is part of it. It can be media for health education that you can use every time and everywhere with direct interaction. So, pregnant woman can use it to improve their knowledge. This study aims to determine whether there is knowledge improvement from pregnant women about danger signs of pregnancy after using augmented reality. This is a quantitative research with one group pre-post test design which requires 30 respondents. The result shows that there is an effect of augmented reality media on the knowledge of pregnant women about the danger signs of pregnancy in the form of increasing knowledge $(p=0,001)$
\end{abstract}

Key words: augmented reality, knowledge, danger signs of pregnancy

\begin{abstract}
ABSTRAK
Salah satu penyebab kematian ibu di Indonesia adalah keterlambatan dalam mengenali tanda bahaya khususnya masa kehamilan. Tenaga kesehatan perlu memperhatikan hal tersebut terutama saat masa pandemi Covid-19 yang menyebabkan terbatasnya waktu dalam pemeriksaan kehamilan, sehingga diperlukan edukasi kesehatan menggunakan media yang tepat. Penggunaan teknologi di era revolusi industri 4.0 saat ini tidak dapat dihindari termasuk dalam dunia kesehatan, salah satunya adalah augmented reality. Media augmented reality merupakan media yang dapat digunakan oleh ibu hamil dimana saja dan kapan saja dengan interaksi secara langsung, sehingga edukasi kesehatan di masa pandemi tetap berlangsung secara maksimal. Penelitian ini bertujuan untuk mengetahui apakah ada perubahan pengetahuan ibu hamil mengenai tanda bahaya kehamilan setelah menggunakan media augmented reality. Penelitian ini merupakan
\end{abstract}


penelitian kuantitatif dengan desain one group pre-post test yang melibatkan responden sebanyak 30 orang. Hasil penelitian menunjukan terdapat pengaruh media augmented reality terhadap perubahan pengetahuan berupa peningkatan pengetahuan ibu hamil mengenai tanda bahaya kehamilan setelah menggunakan media augmented reality $(p=0,001)$.

Kata kunci: Augmented reality, pengetahuan, tanda bahaya, kehamilan

*Korespondensi: Rosnadila Humaira G. Surel: rosnadila17001@mail.unpad.ac.id

\section{PENDAHULUAN}

Berdasarkan data Profil Kesehatan Indonesia tahun 2018, Angka Kematian lbu (AKI) mencapai 305 per 100.000 kelahiran hidup". Faktor penyebab tidak langsung kematian ibu adalah masih banyaknya kasus 3T (tiga terlambat), dimana salah satunya adalah terlambat dalam mengenal tanda bahaya. Kurangnya pengetahuan ibu mengenai tanda bahaya kehamilan menjadi penyebab terlambat dalam mengenal tanda bahaya ${ }^{2}$.

Untuk meningkatkan pengetahuan mengenai kesehatan, pemerintah memiliki upaya dengan promosi atau edukasi kesehatan yang kegiatannya sudah diatur dalam Kepmenkes No. 1147 Tahun 2015. Edukasi kesehatan perlu dilakukan oleh tenaga kesehatan dimana salah satunya adalah bidan. Harapannya dengan kegiatan edukasi kesehatan, mampu meningkatkan pengetahuan ibu hamil mengenai tanda bahaya kehamilan, sehingga mengurangi kasus keterlambatan ${ }^{3}$.

Dalam pelaksanaannya, kegiatan edukasi kesehatan harus diperkuat dengan media yang tepat. Penggunaan media pada saat edukasi kesehatan, umumnya menggunakan media cetak berupa poster, buku, leaflet, banner, atau baliho. ${ }^{3}$ Sebuah penelitian dilakukan oleh Fatimah (2017), telah membandingkan media booklet sebagai media cetak dengan video dalam keterampilan deteksi dini kanker payudara. Hasilnya menyatakan bahwa media booklet dan video dapat meningkatkan keterampilan responden dalam mendeteksi dini kanker payudara melalui kegiatan SADARI (Periksa Payudara Sendiri), dan media video lebih efektif dalam meningkatkan keterampilan responden dalam melakukan SADARI ${ }^{4}$. Penelitian lain yang dilakukan oleh Lanita (2015), menunjukan kelemahan yang dimiliki media booklet yaitu sulit menampilkan gerak, biaya cetakan mahal bila ingin menampilkan ilustrasi dan foto berwarna, proses pencetakan memakan waktu lama, serta jika tidak dirawat dengan baik cepat rusak atau hilang ${ }^{5}$. Hal ini menunjukan bahwa media cetak yang sudah diatur dalam Kepmenkes No.1147 Tahun 2015, sebagai media penunjang promosi kesehatan, kurang efektif.

Dalam hal ini media cetak yang sering digunakan adalah buku KIA. Penggunaan buku KIA sebagai sumber informasi sudah diteliti oleh Napitupulu (2018), pada penelitian yang berjudul "Gambaran Pemanfaatan Buku KIA dan Pengetahuan Ibu Hamil Mengenai Tanda Bahaya Kehamilan". Penelitian tersebut menyatakan bahwa pemanfaatan buku KIA juga memengaruhi pengetahuan ibu mengenai tanda bahaya kehamilan ${ }^{6}$. 
Namun berdasarkan studi pendahuluan yang dilakukan pada 17 ibu hamil, 15 (40\%) diantaranya memiliki buku KIA yang dibaca dengan frekuensi tidak menentu selama satu minggu. Hal ini disebabkan karena responden merasa tidak praktis ketika harus membawa buku kemanapun mereka pergi, sehingga diperlukannya media lain untuk meningkatkan pengetahuan ibu hamil tentang tanda bahaya kehamilan.

Saat ini dunia sedang memasuki era revolusi industri 4.0 dimana konsep automatisasi dilakukan oleh alat dan mesin untuk memudahkan kerja dan aktivitas manusia. Revolusi industri 4.0 mengakibatkan adanya perubahan di berbagai bidang termasuk kesehatan. Salah satu perubahan atau kemajuan yang ada di era ini adalah penggunaan Augmented Reality (AR) sebagai salah satu bidang yang dikembangkan dalam revolusi industri 4.0 selain internet dan video simulasi ${ }^{7}$.

Augmented Reality merupakan media 3D yang menggabungkan benda maya dua dimensi atau tiga dimensi kemudian memproyeksikan benda tersebut dalam waktu nyata. Augmented Reality merupakan objek virtual yang mampu menyampaikan informasi, sehingga dapat membantu manusia dalam melakukan pekerjaannya $^{7}$. Pada teknologi augmented reality ini, pengguna dapat memvisualisasikan objek dalam bentuk tiga dimensi, sehingga objek tampak nyata. Kelebihan dari media ini dibandingkan dengan video dan internet adalah sifatnya yang interaktif, sehingga augmented reality banyak diimplementasikan sebagai media pengajaran ${ }^{8}$.
Banyaknya manfaat yang dapat diperoleh dari penggunaan AR tersebut, diharapkan akan mampu diterapkan pula dalam bidang kesehatan khususnya sebagai media promosi kesehatan. Maka dari itu, tujuan peneliti melakukan penelitian ini adalah untuk mengetahui apakah terdapat pengaruh media augmented reality terhadap perubahan tingkat pengetahuan ibu hamil mengenai tanda bahaya kehamilan.

Penelitian ini menggunakan aplikasi BuMilar (Ibu Hamil AR) dimana aplikasi tersebut dibuat bersama dengan Program Studi Teknik Informatika Fakultas Matematika dan IImu Pengetahuan Alam. Aplikasi ini merupakan aplikasi berbasis teknologi augmented reality yang berisi edukasi mengenai tanda bahaya kehamilan. aplikasi ini dapat diunduh menggunakan perangkat pendukung android yang kemudian penggunaannya dapat dilakukan menggunakan jaringan internet, sehingga diperlukan perangkat berupa handphone yang mendukung serta akses internet.

\section{METODE PENELITIAN}

\section{Rancangan/Desain Penelitian}

Penelitian ini merupakan penelitian kuantitatif dengan desain one group pre-post test. Peneliti nantinya melihat perubahan pengetahuan ibu hamil mengenai tanda bahaya kehamilan sebelum dan sesudah menggunakan media augmented reality BuMilar.

\section{Sumber Data}

Data pada penelitian ini merupakan data primer yang didapatkan langsung dari responden 


\section{Sasaran Penelitian}

Populasi pada penelitian ini adalah semua ibu hamil yang melakukan pemeriksaan ANC di Kota Bandung yang berjumlah 45.189 ibu hamil dengan populasi terjangkau semua ibu hamil yang melakukan pemeriksaan ANC di UPT Caringin, Kecamatan Babakan Ciparay, Kota Bandung yang berjumlah 2.448 . Besar sampel penelitian dihitung menggunakan rumus sampel untuk proporsi tunggal dengan jumlah sampel 29.

\section{Pengembangan Instrumen dan Teknik Pengumpulan Data}

Instrument penelitian yang dipakai adalah kuesioner dengan pertanyaan tertutup dengan skala guttman.

Responden diberikan informasi mengenai penelitian lalu menandatangani lembar informed concent. Kemudian responden mengisi kuesioner pretest, diberikan intervensi dengan menjelaskan penggunaan media dan menggunakan media selama satu minggu kemudian dievaluasi menggunakan kuesioner posttest.

\section{Teknik Analisis Data}

Data yang sudah didapatkan kemudian dianalisis. Data dilakukan uji normalitas menggunakan uji Kolmogorov-Smirnov dengan $p<0,05$. Kemudian analisis dilakukan menggunakan uji Wilcoxon dengan $p$ value 0.001 .

Penelitian ini memiliki persetujuan etik engan nomor etik 900/UN6.KEP/EC2020.

\section{HASIL PENELITIAN}

Tabel 1. Tingkat Pengetahuan Ibu Hamil Mengenai Tanda Bahaya
Kehamilan Sebelum dan Sesudah Menggunakan Media Augmented Reality

\begin{tabular}{lcccc}
\hline \multirow{2}{*}{ Tingkat } & \multicolumn{2}{c}{ Sebelum } & \multicolumn{2}{c}{ Sesudah } \\
\cline { 2 - 5 } Pengetahuan & $\mathrm{n}$ & $(\%)$ & $\mathrm{n}$ & $(\%)$ \\
\hline Baik & 26 & 86,7 & 29 & 96,7 \\
Cukup & 2 & 6,65 & 0 & 0 \\
Kurang & 2 & 6,65 & 1 & 3,3 \\
\hline \multicolumn{2}{c}{ Tabel } & di & atas & \multicolumn{1}{c}{ menunjukan } \\
bahwa & terjadi & & peningkatan
\end{tabular}
pengetahuan ibu hamil mengenai tanda bahaya kehamilan sebelum dan sesudah menggunakan media AR, yang dapat dilihat dari meningkatnya responden dengan pengetahuan baik dari $86,7 \%$ menjadi $96,7 \%$.

Tabel 2. Perubahan Nilai Ibu Hamil Mengenai Tanda Bahaya

Kehamilan Sebelum dan Sesudah Menggunakan Media Augmented Reality

\begin{tabular}{lll}
\hline Perubahan Pengetahuan & $\mathrm{n}$ & $(\%)$ \\
\hline Meningkat & 20 & 66,7 \\
Tetap & 6 & 20 \\
Menurun & 4 & 13,3 \\
\hline
\end{tabular}

Tabel diatas menunjukkan bahwa terdapat perubahan nilai atau skor responden dari sebelum dan sesudah menggunakan media AR yang signifikan berupa peningkatan pengetahuan ibu hamil mengenai tanda bahaya kehamilan setelah menggunakan media AR (66,7\%).. Meskipun kategori responden sebelum dan sesudah menggunakan media AR masih dalam kategori tingkat pengetahuan yang sama, namun ada perubahan nilai.

Tabel 3. Pengaruh Media

Augmented Reality Terhadap

Pengetahuan Ibu Hamil Mengenai Tanda Bahaya Kehamilan

\begin{tabular}{llll}
\hline \multicolumn{3}{c}{ Pengetahuan } & \multirow{2}{*}{$P$ Value } \\
\cline { 1 - 3 } Mean & 80,67 & 87,6 & $\begin{array}{l}\text { Sig (2- } \\
\text { tailed) }\end{array}$ \\
Median & 84 & 92 &, 001 \\
\hline
\end{tabular}


${ }^{*}$ Uji Wilcoxon

Berdasarkan uji yang
dilakukan, hasilnya menunjukan
bahwa ada pengaruh berupa
peningkatan pengetahuan ibu hamil

\section{PEMBAHASAN}

\section{Pengaruh Media Augmented Reality Terhadap Perubahan Pengetahuan Ibu Hamil Mengenai Tanda Bahaya Kehamilan}

Pandemi Covid-19 sedang melanda dunia sejak akhir tahun 2019. Hal tersebut berdampak pada beberapa sektor dunia, salah satunya yang paling berdampak adalah sektor kesehatan. Pada lingkup kesehatan ibu dan anak (KIA), hal ini berdampak pada waktu pemeriksaan menjadi dibatasi. Hal tersebut kemudian menghambat penyampaian informasi atau edukasi kesehatan, sehingga diperlukan media yang mendukung agar waktu yang ada menjadi efektif.

Sejak tahun 2015, dunia sudah dikenalkan dengan adannya revolusi industri 4.0. Revolusi industri 4.0 menerapkan konsep automatisasi yang dilakukan oleh alat dan mesin untuk memudahkan kerja dan aktivitas manusia. Tujuannya untuk mengurangi beban waktu, tenaga, dan biaya. Revolusi industri 4.0 kini juga mulai dimanfaatkan dalam bidang kesehatan dan pendidikan. Salah satu yang diteliti adalah penggunaan Augmented Reality (AR) melihat tujuan dari revolusi industri 4.0, pemanfaatan teknologi yang dikembangkan menjadi solusi untuk edukasi kesehatan dimasa pandemi ini 7,9 .

\section{Augmented Reality (AR)} merupakan salah satu media yang dikembang di masa revolusi industri 4.0. AR dapat menggabungkan visual, audio, dan kinestetik mengenai tanda bahaya kehamilan setelah menggunakan media AR $(p=0.001)$.

pengguna.

Kelebihannya dibandingkan media lain adalah sifatnya yang interaktif dan real time, sehingga dinilai efektif digunakan sebagai media pembelajaran ${ }^{8}$.

Dyah, dkk (2017) melakukan sebuah penelitian untuk mengetahuai pengaruh media augmented reality sebagai media pembelajaran terhadap hasil belajar siswa SD pada mata pelajaran IPA. Hasilnya terdapat peningkatan yang signifikan pada hasil evaluasi belajar siswa yang mendapat pembelajaran IPA menggunakan media AR yaitu sebanyak $98 \%$ sedangkan pembelajaran siswa yang tidak menggunakan media pembelajaran AR sebanyak $89 \%{ }^{10}$.

Selain itu penelitian lain yang dilakukan oleh Arrofa (2018) yang melakukan uji pengetahuan pada dua kelompok, antara pengguna media augmented reality dengan pengguna media gambar. Penelitian ini membuktikan bahwa media augmented reality lebih efektif dalam meningkatkan pengetahuan responden karena dinilai lebih mampu memvisualisasikan objek seolah-olah menjadi nyata ${ }^{11}$.

Pada penelitian ini menunjukan bahwa media AR yang berisi edukasi tentang tanda bahaya kehamilan memberikan pengaruh terhadap pengetahuan ibu hamil. Terdapat perubahan pengetahuan berupa peningkatan jumlah responden dengan pengetahuan kategori baik dan berkurangnya jumlah responden dengan pengetahuan kategori kurang dan 
cukup. Responden dengan pengetahuan baik sebelum menggunakan media AR didapatkan sebanyak $86,7 \%$ yang kemudian meningkat menjadi $96,7 \%$ setelah menggunakan media $A R$, sehingga dapat disimpulkan bahwa media AR efektif dalam memberikan edukasi kesehatan kepada ibu hamil mengenai tanda bahaya kehamilan.

\section{SIMPULAN}

Terdapat

perubahan

pengetahuan ibu hamil mengenai tanda bahaya kehamilan sebelum dan sesudah menggunakan media AR, dengan kategori tingkat pengetahuan baik bertambah dan terdapat peningkatan nilai responden, sebanyak 20 responden $(66,7 \%)$. Media augmented reality memberi pengaruh terhadap perubahan pengetahuan ibu hamil mengenai tanda bahaya kehamilan dengan nilai $p=0.001$.

\section{DAFTAR PUSTAKA}

1. Kurniawan $R$, Yudianto, Hardhana B, Siswanti T. Profil kesehatan 2018. Jakarta: Kemenkes; 2019.

2. Riyanti E, Herniyatun, Astutiningrum D. Deteksi dini tanda bahaya kehamilan dan kesiapan ibu dalam menghadapi persalinan. Jurnal Universitas Muhammadiyah Purworejo. 2019;9:603.

3. Astuti S, Susanti Al, Nurparidah R, Mandiri A. Asuhan ibu dalam masa kehamilan Bandung: Erlangga; 2016.

4. Fatimah M. Perbedaan media promosi kesehatan booklet dan video terhadap keterampilan deteksi dini kanker payudara pada wanita usia subur Placentum. 2017;5:44.

5. Lanita U, Sudargo T, Huriyati E. Pengaruh pendidikan kesehatan melalui short message service (sms) dan booklet tentang obesitas pada remaja overweight dan obesitas. Jurnal Gizi Klinik Indonesia. 2015;12:41.

6. Napitupulu TF, Rahmiati L, Saraswati D, Susanti Al, Setiawati EP. Gambaran pemanfaatan buku KIA dan pengetahuan ibu hamil mengenai tanda bahaya kehamilan. Jurnal Kesehatan Vokasional. 2018;3:22.

7. Bendicho PF. Effect on academic procrastination after introducing augmented reality. EURASIA Journal of Mathematics, Science and Technology Education. 2017;13(1).

8. Abdillah AF, Degeng NS, Husna A. Pengembangan buku suplemen dengan teknologi 3D augmented reality sebagai bahan belajar tematik untuk siswa kelas 4 SD. Jurnal Inovasi Teknologi Pembelajaran. 2020;6:113.

9. Chen P, dkk. A review of using augmented reality in education from 2011 to 2016 . Springer Link. 2016;2:13.

10. Vitalocca D, Mardiana. Pengaruh media augmented reality sebagai media pembelajaran terhadap hasil belajar siswa SD pada mata pelajaran IPA. Journal eprints UNM. 2017;1:172.

11. Acesta A, Nurmaylany $M$. Pengaruh penggunaan media augmented reality terhadap hasil belajar siswa. Jurnal Pendidikan Guru Sekolah Dasar. 2018;4:350. 